\title{
Review
}

\section{Current Status of Fractional Laser Resurfacing}

\author{
Paul J. Carniol, MD; Mark M. Hamilton, MD; Eric T. Carniol, MD
}

Fractional lasers were first developed based on observations of lasers designed for hair transplantation. In 2007, ablative fractional laser resurfacing was introduced. The fractionation allowed deeper tissue penetration, leading to greater tissue contraction, collagen production and tissue remodeling. Since then, fractional erbium:YAG resurfacing lasers have also been introduced. These lasers have yielded excellent results in treating photoaging, acne scarring, and dyschromia. With the adjustment of microspot density, pulse duration, number of passes, and fluence, the surgeon can adjust the treatment effects. These lasers have allowed surgeons to treat patients with higher Fitzpatrick skin types (types IV to $\mathrm{VI}$ ) and greater individualize treatments to various facial subunits. Immunohistochemical analysis has demonstrated remodeling effects of the tissues for several months, producing longer lasting results. Adjuvant treatments are also under investigation, including concomitant face-lift, product deposition, and platelet-rich plasma. Finally, there is a short recovery time from treatment with these lasers, allowing patients to resume regular activities more quickly. Although there is a relatively high safety profile for ablative fractionated lasers, surgeons should be aware of the limitations of specific treatments and the associated risks and complications.

JAMA Facial Plast Surg. 2015;17(5):360-366. doi:10.1001/jamafacial.2015.0693 Published online July 2, 2015.

\author{
Author Affiliations: Department of \\ Otolaryngology-Head and Neck \\ Surgery, Rutgers New Jersey Medical \\ School, Summit (P. J. Carniol); \\ Department of Otolaryngology-Head \\ and Neck Surgery, Indiana University \\ School of Medicine, Greenwood \\ (Hamilton); Rutgers New Jersey \\ Medical School, Newark (E. T. Carniol) \\ Corresponding Author: Paul J. \\ Carniol, MD, Department of \\ Otolaryngology-Head and Neck \\ Surgery, Rutgers New Jersey Medical \\ School, 33 Overlook Rd, Ste 401, \\ Summit, NJ 07901 (pjclaser@ao \\ .com).
}

$\mathrm{I}$ thas been a decade since the development of fractional lasers. ${ }^{1}$ The concept of fractional laser resurfacing was first developed from lasers for hair transplantation. These lasers were used to make tiny 1-mm scalp wounds for placement of grafts. ${ }^{2} \mathrm{Al}-$ though there may be controversy over use of lasers for hair restoration, it was readily apparent that the small laser wounds healed quickly with minimal scarring

This led to fractional laser studies by Manstein et al ${ }^{1}$ at the Wellman Center for Photomedicine. Initially, they evaluated the use of groups nonablative laser "microspots" as an alternative to resurfacing or using nonablative devices to treat a broader area.

From this concept, the first nonablative fractional laser, the Fraxel (Reliant Technologies Inc [now Solta, a subsidiary of Valeant Pharmaceuticals]), was developed. ${ }^{1}$

This laser emits a 1550-nm wavelength, which is highly absorbed by water. As a nonablative laser it creates hundreds of microscopic columns of thermal injury. These have been called microthermal zones. Circumferentially surrounding each of these zones is unlasered tissue, which contributes to the rapid healing. After treatment, reepithelialization typically occurs within 24 hours.

With nonablative fractional laser treatments, patients often experience mild erythema, which resolves within a week. Makeup can be applied shortly after treatment. The mild swelling that does develop resolves in a few days, and there is minimal downtime.

Studies ${ }^{1,3}$ demonstrated rhytid reduction as well as improved skin texture and skin tightening. In addition, the adverse effect profile was much improved compared with traditional laser resurfacing. Nonablative fractional technology expanded the potential suitable candidates for laser treatment. Owing to the longer wavelength of this laser, there is less melanin absorption. This allows treatment of higher Fitzpatrick skin types (types IV-VI) ${ }^{4}$ with less risk of dyschromia (Figure 1). Some of these lasers proved surprisingly efficient in treating scars (Figure 2). Similar devices at wavelengths of 1320,1440 , and $1540 \mathrm{~nm}$ by other manufacturers followed.

In 2007, Hantash et al ${ }^{5}$ introduced the clinical and histologic results of a new ablative fractional carbon dioxide laser. This began the era of ablative fractional resurfacing. Unlike nonablative fractional treatments, in which the stratum corneum remained intact, these ablative fractional devices vaporize a complete column of tissue. Fractional resurfacing skin tissue contraction has been shown to persist for at least 1 year after the procedure. ${ }^{6,7}$

Frequently, patients treated with ablative fractional lasers have a longer recovery than those treated with nonablative fractional lasers. Depending on multiple treatment and patient variables this often requires 3 to 5 days for reepithelialization and initial healing. Because tissues around each of these lasered columns are not directly treated, healing can occur from the tissues around the ablated column as well as from the base of the column. This rapid reepithelialization from the untreated surrounding skin decreases the challenges that can be associated with recovery as well as risk of infection, acneiform eruptions, erythema, and scarring. ${ }^{8}$

Several studies have shown significant skin changes from fractional resurfacing. One study ${ }^{9}$ that used high-resolution ultrasonography to measure dermal thickness revealed a $25 \%$ mean increase in dermal thickness. At the histochemical level, fractional resurfacing stimulates collagen contraction and neocollagenesis. ${ }^{10-12}$

Immunohistochemical stains show cellular markers for neocollagenesis, proinflammatory cytokine production, metaloproteinases, and type I and type III collagen. ${ }^{13-15}$ This process continues with ongoing tissue remodeling for up to 6 months. In a related process, 
Figure 1. A 38-Year-Old Woman With Fitzpatrick Type IV Skin Who Underwent 5 Treatments With the Fraxel Laser

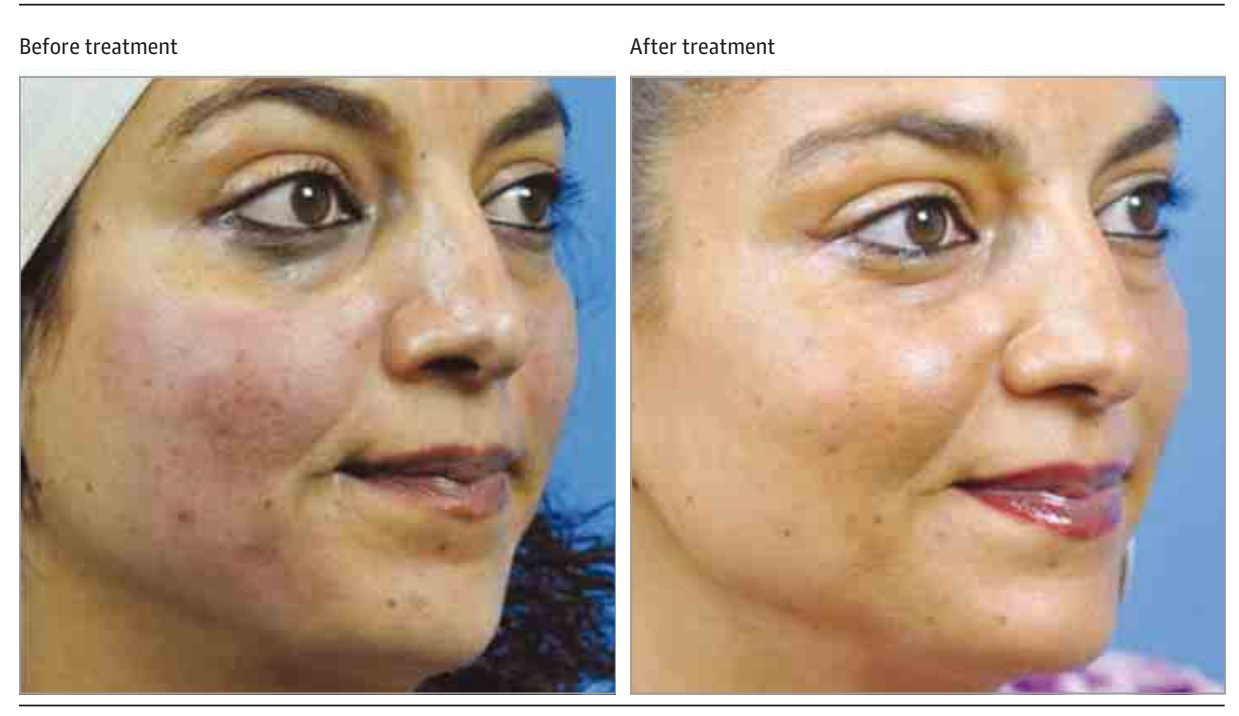

Figure 2. A Patient Who Underwent 5 Treatments With the Fraxel Laser

Before treatment

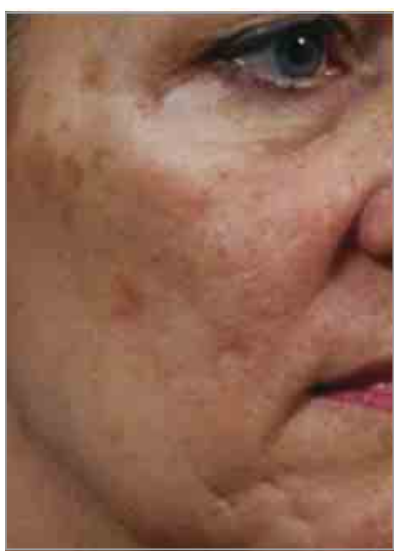

After treatment

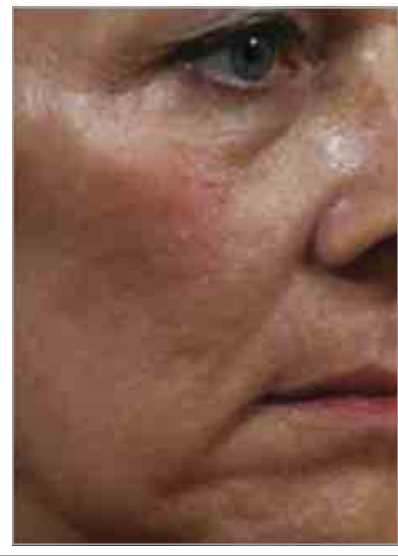

skin contraction from fractional resurfacing has been shown to persist for 1 year after the procedure. ${ }^{6,7}$

Fractional resurfacing brought other advantages as well. Unlike fully ablative treatments, there is minimal risk of hypopigmentation. Hunzeker et al $^{8}$ reported a series of 2000 treatments without a single case of case of hypopigmentation. In addition, this same large study reported not a single incidence of scarring. While results comparable with those of full-field traditional laser resurfacing remained to be seen, a new viable alternative had arisen.

\section{Ablative Fractional Resurfacing}

A variety of devices have followed for ablative fractional resurfacing (AFR) since 2007. These vary in several ways including wavelength (carbon dioxide, erbium, YSGG), delivery system (rolling vs stamp), microspot diameter, pulse duration, density, and depth of penetration.
Several studies ${ }^{16,17}$ have shown consistent improvement for rhytids, photodamage, and scars. In addition, histological analysis ${ }^{18}$ has demonstrated collagen remodeling up to 3 months after the procedure. Despite marketing claims to the contrary, studies comparing these devices have shown no significant differences in pain, downtime, and, most important, results. ${ }^{19}$

In addition, several parameters can be adjusted to alter treatment effects. The first is laser fluence, which is the laser energy per unit area of tissue. Aesthetic outcome, as well as rate of complications, can vary with the fluence. The second is microspot density, which is used to adjust the resurfaced area percentage. Microspot density is important. One of the mechanisms of healing is epithelial migration from adjacent untreated skin. Furthermore, tissue cooling occurs by heat transfer to the untreated area around each microspot. Dermal bulk heating varies directly with microspot density. Therefore, microspot density also affects healing and the risk of complications.

For most devices, the diameter of the laser microspot is not adjustable. Another parameter is microspot pulse duration. Adjacent tissue and dermal bulk heating also vary directly with the pulse duration.

Microspots vary in diameter between devices and can ablate to a variable depth into the dermis. With microspot technology, depths of up to $2000 \mu \mathrm{m}$ have been achieved. ${ }^{8}$ The percentage of the skin surface area that is ablated can also be varied. The higher the density, the higher the percentage of skin treated. Depending on the design parameters of the fractional laser, increasing resurfacing density beyond a certain level will more closely approximate carbon dioxide laser resurfacing. As such, there can be an increase in recovery time and risk profile.

Increasing the percentage of treated area can be achieved by increasing the density or using more than 1 pass to achieve a greater percentage of lasered area. Using more than 1 pass to increase the surface area treated allows for dermal cooling between passes. The thermal effects of using more than 1 pass to increase the percentage of treated surface area differ from that of increasing the density. 
Pulse duration also can have a significant effect on clinical results. Tierney et al ${ }^{20}$ performed a study to analyze the effect of microspot pulse duration on depth of resurfacing. Ten patients were treated with an ablative fractional carbon dioxide laser. The pulse duration was randomized from 500 to 1800 microseconds. Fluence and density were constant. Postauricular skin biopsies were taken 1 hour, 1 week, and 8 weeks after treatment. Histologic analysis revealed that greater pulse duration yielded an increase in ablation depth. Although not evaluated in this study, ${ }^{2 \mathrm{O}}$ it should be noted that increased pulse duration increases adjacent tissue thermal effects and dermal bulk heating.

Fluence can also affect depth of ablation as well as diameter. Hantash et al ${ }^{5}$ performed an ex vivo histologic study evaluating the effect of changes in fluence. In this study, they found that with the fractional carbon dioxide laser studied, a $150 \%$ increase in pulse energy from 9.2 to 23.3 resulted in a $66 \%$ increase in ablation diameter. This also resulted in a $99 \%$ increase in ablative depth.

\section{Laser Treatment Parameters}

It is not possible to give one set of parameters that can be used in most patients to achieve a predicted outcome. Skin varies among anatomical locations and patients.

\section{Ablative Fractional Resurfacing Indications}

\section{Photoaging}

Ablative fractional resurfacing has demonstrated excellent improvement in the treatment of photoaging ${ }^{21,22}$ (Figure 3). A study by Clementoni et $\mathrm{al}^{17}$ showed not only excellent improvement in photoaging in a large series, but also persistence of the results 2 years after treatment. We have found that after fractional carbon dioxide resurfacing, patients continue to improve for at least 6 months. This is consistent with the reported histochemical effects of fractional resurfacing. ${ }^{13,14}$

A broad study looking at 4 different manufactured brands of fractional resurfacing devices (Fraxel Repair [Solta Medical Inc], Active and Deep FX [Lumenis], Quadralase [Candela], and Pearl Fractional [Cutera]) demonstrated consistent improvement in photoaging treated with ablative fractional devices. ${ }^{19}$ Consistent improvement was noted in skin texture, lentigines, pore size, and rhytids. In addition, it was noted that all 4 of the commonly used fractional devices resulted in statistically the same downtime and results.

\section{Acne Scarring}

A wide variety of devices were used to treat acne scars in the past, both ablative and nonablative. ${ }^{23}$ Ablative fractional resurfacing offers the unique advantage over other systems of safe penetration into the low reticular dermis allowing for deep skin remodeling.

Studies have demonstrated consistent improvement of acne scars with fractional lasers. A study ${ }^{24}$ evaluating the effect of treatment intervals found significant improvement in acne scars with fractional carbon dioxide laser. Thirteen patients received 2 treatments at either 1- or 3-month intervals for acne scarring. In addition to noting clinically significant improvement in all patients, no difference in clinical results or adverse effects was noted between the 2 groups. In another study ${ }^{25}$ of 15 patients treated for moderate to severe acne scarring, $66.8 \%$ had an improvement after 2 to 3 fullface fractional carbon dioxide laser treatments. In patients with ice-pick scars from acne, Trimas ${ }^{26}$ recommended surgical excision, followed by carbon dioxide laser resurfacing.

Other scars, including surgical scars, have been treated with fractionated lasers. A prospective blinded study ${ }^{27}$ of 15 patients treated with fractional carbon dioxide for postsurgical scars noted clinically significant improvement in the treated half of the scar. Another study ${ }^{28}$ using a nonablative 1550 -nm laser demonstrated clinically significant improvements in both the patient and independent observer appreciation of scar pigmentation and/or color, thickness, irregularity, and relief.

\section{Product Deposition}

The channels created by fractional resurfacing can be used for the introduction of products into the skin, which was not possible in the past. In 1 study of the treatment for acne scarring. Waibel et $\mathrm{al}^{29}$ used these channels to allow deeper penetration of topical corticosteroids. They reported that this enhanced the outcome of treating with a fractional laser. A more recent study by Rkein et al ${ }^{30}$ used this same concept to deliver topically applied poly-L-lactic acid (PLLA) through the skin. They reported a seemingly synergistic benefit of ablative fractional laser resurfacing and PLLA in the treatment of atrophic scarring. Even after these studies, there is still controversy about this type of product deposition.

\section{Platelet-Rich Plasma}

Another recent study ${ }^{31}$ evaluated the effects of platelet-rich plasma (PRP) administration on posttreatment healing time and adverse events in patients undergoing fractional carbon dioxide laser using the forearm as the test site. Postoperatively, patients treated with PRP were noted to have decreased edema and improved erythema, in comparison with those treated with saline. Reepithelialization rates were noted to be similar between the PRP-treated areas and controls. Further research is necessary to assess such effects when the procedure is performed on the face.

\section{Dyschromia}

After fractional resurfacing, within 24 to 48 hours, keratinocytes and stem cells migrate from adjacent nonlasered tissue into ablated zones. Healing also occurs from the deeper skin appendages. These healing mechanisms have an "averaging" effect on dyschromia, thereby giving the skin a more even pigmentation.

This theory of "melanin shuttle" has been most beneficial with the nonablative fractional devices. Several studies ${ }^{32,33}$ have demonstrated a reduction in melasma with these devices. It should be noted that this does not affect the tendency to form melasma. Thus, even after treatment, it is possible for melasma to recur in the future.

Reduction does require multiple treatments. Astudy ${ }^{34}$ has demonstrated effective treatment of melasma in Chinese patients with limited results. Despite this study, we are still cautious about treating these patients with a fractional carbon dioxide laser, considering the possible risk of inducing dyschromia. Benefits have been reported for other types of pigmentation as well. ${ }^{35,36}$ 
Figure 3. A Patient Who Underwent Full-Face Fractional Treatment With the Carbon Dioxide Laser at a Setting of $100 \mathrm{~mJ}$, Density 3; $80 \mathrm{~mJ}$, Density 3; Periorbital

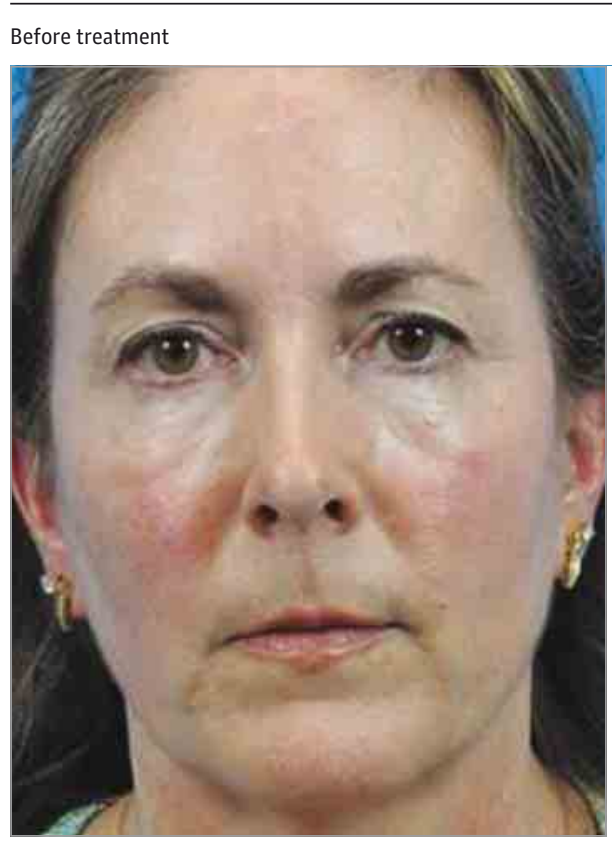

After treatment

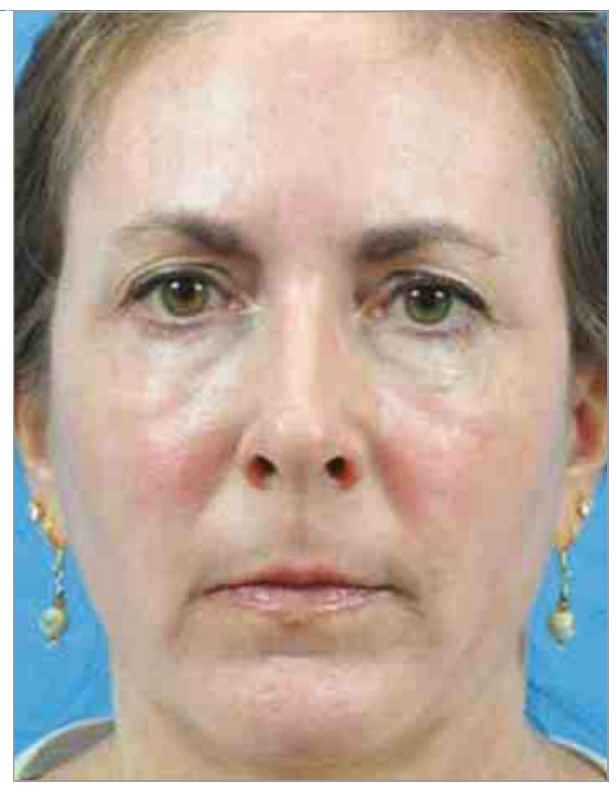

Before treatment

After treatment
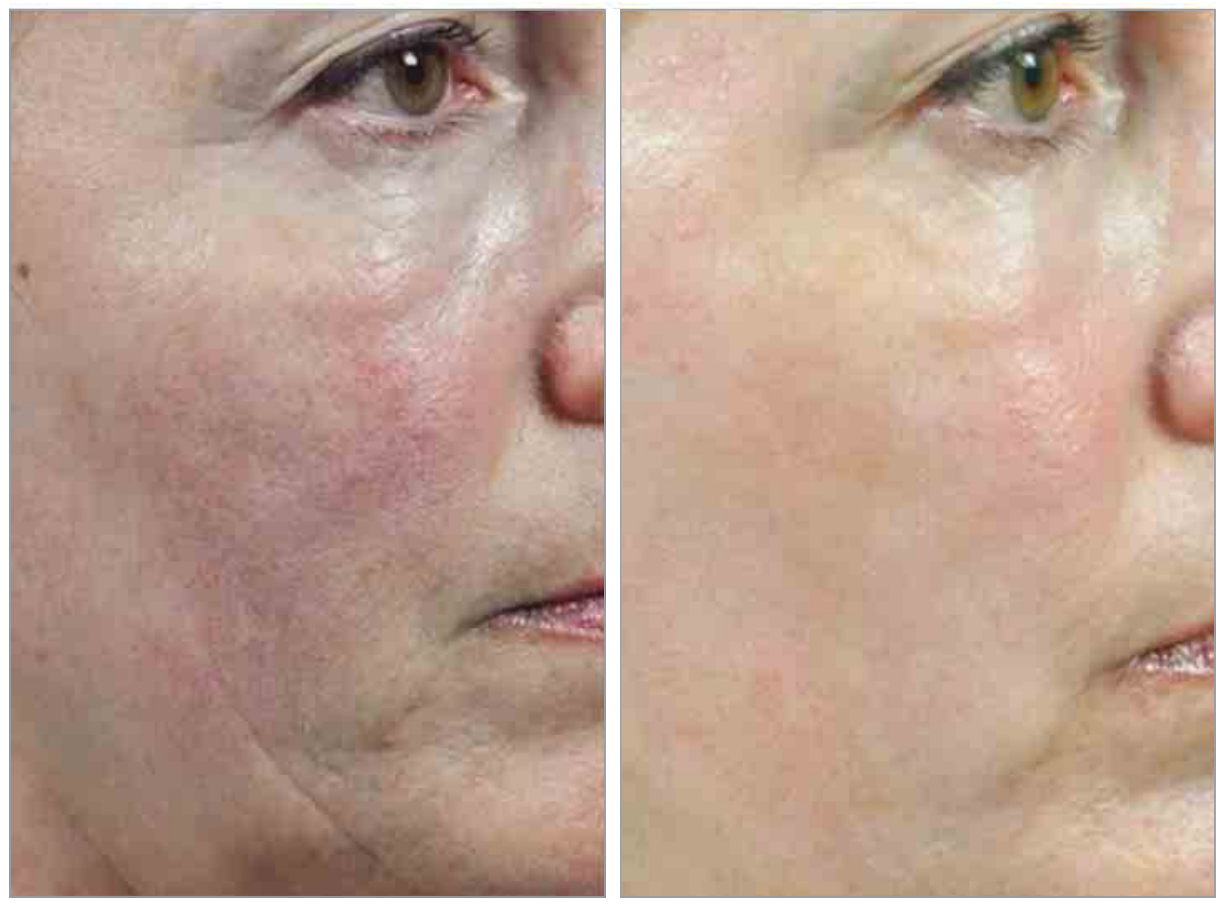

\section{Combined Surgical Procedures}

For years, the idea of resurfacing the skin at the same time as surgical lifting remained controversial. Gradually, some surgeons began to combine the 2 with successful and safe results. In 2002, Koch and Perkins ${ }^{37}$ reviewed the literature and provided their own successful series to demonstrate the safety of performing a face-lift and simultaneous full-face carbon dioxide laser resurfacing.
It seemed only logical to combine the less invasive fractional resurfacing with lifting procedures. In 2012, Truswell ${ }^{38}$ presented his experience of combining full-face AFR with simultaneous face-lift. In a series of 42 patients, there were no incidence of hypopigmentation, infection, or skin necrosis. Four patients had hyperpigmentation, all of which resolved without consequence. In addition, other procedures performed at the same time included endoscopic forehead-lift, upper and lower blepharoplasty, and chin augmentation (Figure 4). Truswell ${ }^{38}$ emphasized the importance of technique to 
Figure 4. Full-Face Fractional Carbon Dioxide Laser Treatment at a Setting of $100 \mathrm{~mJ}$, Density 3, Face; $80 \mathrm{~mJ}$, Density 3, Periorbital; and Transconjunctival Lower Blepharoplasty

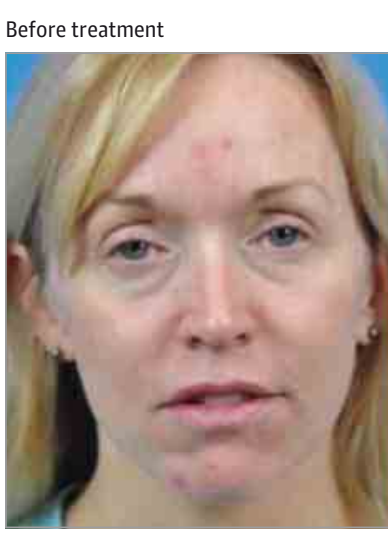

After treatment

Before treatment

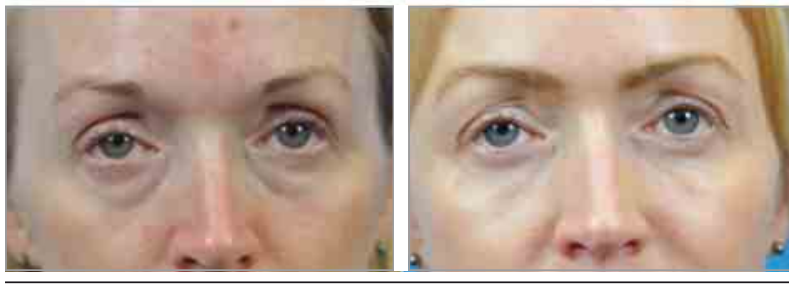

preserve flap vascularity. This involved insuring a thick flap, decreasing laser energy, and feathering over elevated tissue.

Others have reported safely combined AFR and face-lifting. Duplechain ${ }^{39}$ went further, combining resurfacing with surgery and volume restoration. This combination of lifting with resurfacing (fractional or full field) could be combined with fat grafting for maximal rejuvenation. Duplechain ${ }^{39}$ recommended against using the smaller spot size with the Lumenis Encore laser. This is a deeper penetrating fractional laser on a skin flap.

We believe that the safety of simultaneous fractional resurfacing over an elevated face-lift flap is technique- and technologydependent. Therefore, if performed, this procedure should be done judiciously (Figure 5).

\section{Fractional Laser Technique}

One of the main mechanisms for skin rejuvenation by fractional resurfacing is to achieve sufficient thermal stimulation of the dermis while minimizing the risk of complications. In terms of specific procedural technique, there are multiple variables that should be considered. These will affect both the details of the procedure as well as the laser parameters.

There is considerable skin variation among patients. This can relate to several factors, including but not limited to the patient's age, social habits, skin care, prior sun exposure, Fitzpatrick skin type, and medical conditions. For example, an older patient with thinner skin cannot tolerate the same treatment as someone in his or her $40 \mathrm{~s}$ who has thicker, more robust skin.

Even on the same patient, skin varies depending on specific location. For example, compare lower eyelid skin with immediately ad-
Figure 5. Cheek Skin Following Face-lift and Full-Face Fractional Carbon Dioxide Laser Resurfacing at a Setting of $100 \mathrm{~mJ}$, Density 3

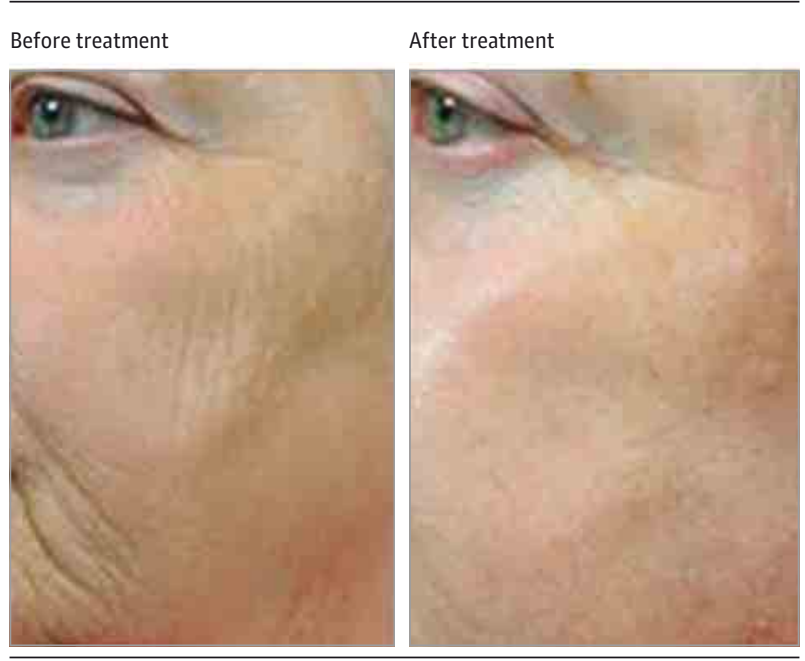

jacent cheek skin. They are very different. These variations should be considered whenever performing a laser procedure to optimize the outcome and minimize the chance of complications.

\section{Laser Skin Care}

\section{Pre-Laser Treatment Skin Care}

Every attempt is made to start patients on a preoperative regimen a full month in advance. Patients may be started on a bleaching cream (hydroquinone, 4\%) daily in advance of their procedure, especially if the patient has a darker skin type. Patients can also be scheduled for a glycolic acid peel 2 to 4 weeks prior to their laser treatment.

\section{Post-Laser Treatment Care}

Following the laser procedure, patients are instructed in a specific regimen of skin care. For those patients undergoing nonablative fractional resurfacing, care is minimal. We recommend using a mild, fragrance-free cleanser and moisturizer for the first week after treatment. Strict sun avoidance is emphasized. Following week 1, patients may resume their regular skin care regimen.

For those patients undergoing ablative fractional resurfacing, patients begin a process of frequent cleaning. Some surgeons will recommend using just tap water and gentle gauze followed by application of a bland lubricating ointment, such as Aquaphor (Beiersdorf Inc) or petrolatum. Others will use antifungal and/or antibiotic solutions, such as dilute acetic acid ( $1 \mathrm{tsp}$ white vinegar in 2 cups of water). Patients are encouraged to shower at least once a day. This is continued until resurfacing is complete, typically between days 4 to 6 after the procedure.

Once resurfacing is complete, patients are encouraged to wear mineral-based makeup. Gentle, fragrance-free cleansers and moisturizers are recommended until all redness has faded. Patients can be started on a topical steroid (hydrocortisone, $2 \%$ ) to help with irritation and well as expedite fading of erythema. During this period patients are strongly urged to avoid prolonged sun exposure and to wear sunscreen daily. 
Once erythema has faded, patients are encouraged to continue with a regular skin care regimen that includes sunscreen and at least 1 prescription-strength product. Tretinoin or retinol products are an excellent choice for most patients. Patients are also encouraged to follow good skin care practices, including sun avoidance.

\section{Regular Use of Sunscreen and Avoidance of Tanning} Previous studies have documented the importance of prophylactic therapy, even in those without a history of herpetic infections. All patients are placed on antiviral prophylaxis. This begins the day before their procedure in those without a history of herpetic infections and 3 days before in those with a history of herpetic infections. Valacyclovir is typically used because of the ease of the twice-a-day dosing. Therapy is continued for a total of 10 days.

\section{Fractional Carbon Dioxide Laser vs Carbon Dioxide Laser Resurfacing} Nonfractional carbon dioxide resurfacing lasers require a longer recovery and have a higher adverse effect profile than fractional ablative resurfacing or nonablative lasers. However, it should also be noted that they can produce a more dramatic result. ${ }^{39}$ Ablative resurfacing can be performed with the carbon dioxide or erbium: yttrium-aluminum-garnet (Er:YAG) lasers. Ablative laser resurfacing is most commonly used for photoaging, rhytids, laxity, and scarring. While rhytids and dyschromias are highly responsive to ablative resurfacing, scars may be less responsive. ${ }^{3,40}$

Even with the advent of fractional carbon dioxide resurfacing, there is still a role for ablative full-field carbon dioxide laser resurfacing. Patients undergoing this procedure should be highly motivated. In having this procedure, patients are anticipating a more dramatic result, and they are also accepting a longer recovery and associated risks. They should be willing to wear makeup until the postresurfacing pinkness resolves. They also should have a lifestyle that allows avoidance or at least extreme caution with sun exposure. These are typically patients in their late 50s to 70s who have a lifestyle that allows them to have the recovery time and have moderate to deep rhytids with significant associated actinic changes.

Alternatively, the patient undergoing fractional resurfacing is typically someone with an active lifestyle who cannot take time from their busy schedule for a longer and more involved recovery. These patients would feel constrained if they had to consider daily camouflage makeup. The patient undergoing fractional laser resurfacing frequently is not willing to take time from their busy schedule for a longer recovery. Most of the first author's patients prefer fractional resurfacing.

\section{Complications}

One of the main advantages of fractional resurfacing has been the lower incidence of complications, especially with the nonablative devices. ${ }^{1}$ Studies with ablative fractional devices also show a lower risk profile than full-field ablative resurfacing. ${ }^{8}$ That said, complications still remain an issue. In a retrospective study ${ }^{41}$ of 374 patients who had deep resurfacing with a fractional carbon dioxide laser there were adverse events in $16.8 \%$ of patients. These included acneiform eruptions, herpes simplex eruptions, bacteria and candida infections, hyperpigmentation, persistent erythema, and contact dermatitis. In the study by Campbell and Goldman ${ }^{42}$ of 287 patients, $13.9 \%$ experienced complications, including allergic or contact dermatitis, acneiform eruptions, persistent erythema, and herpes simplex.

Even though the resulting numbers from these studies are significant, they represents a lower overall occurrence of adverse events and better safety profile than the fully ablative laser resurfacing lasers with a $36 \%$ incidence rate of hyperpigmentation, ${ }^{3}$ the most common adverse effect.

It should be noted that cervical skin, with fewer pilosebaceous units and a different blood supply than the face, is at greater risk for complications. This increases in the lower two-thirds of the neck. Avram et al ${ }^{43}$ reported 5 cases of patients who presented for treatment of hypertrophic scarring of the neck following fractional ablative resurfacing. Duplechain ${ }^{39}$ highlighted these differences and recommended caution with resurfacing, especially in the lower neck. Treatment of the neck with fractional resurfacing should be approached with caution, lower fluence, lower density, and shorter pulse duration settings.

Treatment with lasers, as with any other surgical procedure, can lead to undesirable outcomes and patient dissatisfaction, possibly resulting litigation. A recent review ${ }^{44}$ of laser-related litigation demonstrated that permanent injury and disfigurement were the 2 most cited alleged factors. More than half of the cases were from cutaneous treatments, with age-related changes, acne scars, and hair removal the most frequent indications leading to lawsuit.

\section{Conclusions}

With the introduction of fractional technology, we have entered a new era of laser skin rejuvenation. Studies have shown that fractional treatments offer patients many of the same benefits of traditional carbon dioxide laser resurfacing with less downtime and a lower risk profile. The ideal patients have mild to moderate sun damage, superficial rhytids, are still active and in the sun, and accepting of more subtle improvement. This new technology will continue to evolve with altered treatment parameters and new systems. While there remains a place for those desiring the maximal results of traditional full-field ablative carbon dioxide laser resurfacing, the future is bright for most patients looking for the alternative options that current fractional resurfacing devices provide.

\section{ARTICLE INFORMATION}

Accepted for Publication: April 14, 2015.

Published Online: July 2, 2015. doi:10.1001/jamafacial.2015.0693.

Author Contributions: Dr P. J. Carniol had full access to all of the data in the study and takes responsibility for the integrity of the data and the accuracy of the data analysis. Study concept and design: All authors. Acquisition, analysis, or interpretation of data: All authors.

Drafting of the manuscript: All authors. Critical revision of the manuscript for important intellectual content: All authors.
Administrative, technical, or material support: All authors.

Study supervision: P. J. Carniol.

Conflict of Interest Disclosures: Dr P. J. Carniol has been a member of the speakers bureau for Cutera and Ellman-Cynosure and has invested in Carniol Investments, LLC. Carniol Investments has invested 
in Rohrer Aesthetics. Dr Hamilton has been a member of the speakers bureau for Allergan. No other disclosures are reported.

\section{REFERENCES}

1. Manstein D, Herron GS, Sink RK, Tanner H, Anderson RR. Fractional photothermolysis: a new concept for cutaneous remodeling using microscopic patterns of thermal injury. Lasers Surg Med. 2004;34(5):426-438

2. Saedi N, Jalian HR, Petelin A, Zachary C. Fractionation: past, present, future. Semin Cutan Med Surg. 2012;31(2):105-109.

3. Alexiades-Armenakas MR, Dover JS, Arndt KA The spectrum of laser skin resurfacing: nonablative, fractional, and ablative laser resurfacing. J Am Acad Dermatol. 2008;58(5):719-737.

4. Fitzpatrick TB. The validity and practicality of sun-reactive skin types I through VI. Arch Dermatol. 1988;124(6):869-871.

5. Hantash BM, Bedi VP, Chan KF, Zachary CB. Ex vivo histological characterization of a novel ablative fractional resurfacing device. Lasers Surg Med. 2007;39(2):87-95

6. Bonan P, Campolmi P, Cannarozzo G, et al. Eyelid skin tightening: a novel "niche" for fractional $\mathrm{CO}_{2}$ rejuvenation. J Eur Acad Dermatol Venereol. 2012; 26(2):186-193.

7. Ancona $\mathrm{D}$, Katz BE. A prospective study of the improvement in periorbital wrinkles and eyebrow elevation with a novel fractional $\mathrm{CO} 2$ laser: the fractional eyelift. JDD. 2010;9(1):16-21.

8. Hunzeker CM, Weiss ET, Geronemus RG. Fractionated $\mathrm{CO} 2$ laser resurfacing: our experience with more than 2000 treatments. Aesthet Surg J. 2009;29(4):317-322.

9. Naouri M, Atlan M, Perrodeau E, et al. High-resolution ultrasound imaging to demonstrate and predict efficacy of carbon dioxide fractional resurfacing laser treatment. Dermatol Surg. 2011;37 (5):596-603.

10. Orringer JS, Johnson TM, Kang S, et al. Effect of carbon dioxide laser resurfacing on epidermal p53 immunostaining in photodamaged skin. Arch Dermatol. 2004;140(9):1073-1077.

11. Seckel BR, Younai S, Wang K-K. Skin tightening effects of the ultrapulse $\mathrm{CO} 2$ laser. Plast Reconstr Surg. 1998;102(3):872-877

12. Ross EV, McKinlay JR, Anderson RR. Why does carbon dioxide resurfacing work? A review. Arch Dermatol. 1999;135(4):444-454.

13. Orringer JS, Rittié L, Baker D, Voorhees JJ, Fisher $\mathrm{G}$. Molecular mechanisms of nonablative fractionated laser resurfacing. Br J Dermatol. 2010; 163(4):757-768

14. Reilly MJ, Cohen M, Hokugo A, Keller GS. Molecular effects of fractional carbon dioxide laser resurfacing on photodamaged human skin. Arch Facial Plast Surg. 2010;12(5):321-325.

15. Berlin AL, Hussain M, Phelps R, Goldberg DJ. A prospective study of fractional scanned nonsequential carbon dioxide laser resurfacing: a clinical and histopathologic evaluation. Dermatol Surg. 2009;35(2):222-228.

16. Tretti Clementoni M, Galimberti M, Tourlaki A, Catenacci M, Lavagno R, Bencini PL. Random fractional ultrapulsed $\mathrm{CO} 2$ resurfacing of photodamaged facial skin: long-term evaluation. Lasers Med Sci. 2013:28(2):643-650.

17. Clementoni MT, Lavagno R, Munavalli G. A new multi-modal fractional ablative $\mathrm{CO} 2$ laser for wrinkle reduction and skin resurfacing. J Cosmet Laser Ther. 2012;14(6):244-252.

18. Longo C, Galimberti M, De Pace B, Pellacani G Bencini PL. Laser skin rejuvenation: epidermal changes and collagen remodeling evaluated by in vivo confocal microscopy. Lasers Med Sci. 2013;28 (3):769-776

19. Karsai $S$, Czarnecka $A$, Jünger $M$, Raulin $C$ Ablative fractional lasers ( $\mathrm{CO}(2)$ and $\mathrm{Er}: Y A G)$ : a randomized controlled double-blind split-face tria of the treatment of peri-orbital rhytides. Lasers Surg Med. 2010;42(2):160-167.

20. Tierney EP, Eisen RF, Hanke CW. Fractionated CO2 laser skin rejuvenation. Dermatol Ther. 2011;24 (1):41-53.

21. Geronemus RG. Fractional photothermolysis: current and future applications. Lasers Surg Med. 2006;38(3):169-176.

22. Rahman Z, Alam M, Dover JS. Fractional Laser treatment for pigmentation and texture improvement. Skin Therapy Lett. 2006;11(9):7-11.

23. Carniol PJ, Harmon CB, Hamilton MM. Ablative Laser Facial Skin Rejuvenation. In: Papel ID, ed.

Facial Plastic and Reconstructive Surgery. 3rd ed. New York, NY: Theime; 2009:321-329.

24. Bjørn M, Stausbøl-Grøn B, Braae Olesen A, Hedelund $L$. Treatment of acne scars with fractional $\mathrm{CO} 2$ laser at 1-month versus 3-month intervals: an intra-individual randomized controlled trial. Lasers Surg Med. 2014:46(2):89-93.

25. Chapas AM, Brightman L, Sukal S, et al. Successful treatment of acneiform scarring with $\mathrm{CO} 2$ ablative fractional resurfacing. Lasers Surg Med 2008;40(6):381-386

26. Trimas SJ. Facial acne scarring: ten years of treatment with the carbon dioxide laser. Arch Facial Plast Surg. 2011;13(1):62-64

27. Lee SH, Zheng Z, Roh MR. Early postoperative treatment of surgical scars using a fractional carbon dioxide laser: a split-scar, evaluator-blinded study. Dermatol Surg. 2013;39(8):1190-1196.

28. Pham AM, Greene RM, Woolery-Lloyd H Kaufman J, Grunebaum LD. 1550-nm nonablative laser resurfacing for facial surgical scars. Arch Facial Plast Surg. 2011;13(3):203-210.

29. Waibel JS, Wulkan AJ, Shumaker PR. Treatmen of hypertrophic scars using laser and laser assisted corticosteroid delivery. Lasers Surg Med. 2013;45 (3):135-140

30. Rkein A, Ozog D, Waibel JS. Treatment of atrophic scars with fractionated $\mathrm{CO} 2$ laser facilitating delivery of topically applied poly-L-lactic acid. Dermatol Surg. 2014;40(6):624-631.

31. Kim H, Gallo J. Evaluation of the effect of platelet-rich plasma on recovery after ablative fractional photothermolysis. JAMA Facial Plast Surg. 2015:17(2):97-102

32. Rokhsar CK, Fitzpatrick RE. The treatment of melasma with fractional photothermolysis: a pilot study. Dermatol Surg. 2005;31(12):1645-1650.

33. Goldberg DJ, Berlin AL, Phelps R. Histologic and ultrastructural analysis of melasma after fractional resurfacing. Lasers Surg Med. 2008;40(2):134-138.

34. Naito SK. Fractional photothermolysis treatment for resistant melasma in Chinese females. J Cosmet Laser Ther. 2007;9(3):161-163.

35. Izikson L, Anderson RR. Resolution of blue minocycline pigmentation of the face after fractional photothermolysis. Lasers Surg Med. 2008;40(6):399-401.

36. Chrastil B, Glaich AS, Goldberg LH, Friedman PM. Fractional photothermolysis: a novel treatment for disseminated superficial actinic porokeratosis. Arch Dermatol. 2007;143(11):1450-1452

37. Koch BB, Perkins SW. Simultaneous rhytidectomy and full-face carbon dioxide laser resurfacing: a case series and meta-analysis. Arch Facial Plast Surg. 2002;4(4):227-233.

38. Truswell WH IV. Combining fractional carbon-dioxide laser resurfacing with face-lift surgery. Facial Plast Surg Clin North Am. 2012;20(2):201-213, vi.

39. Duplechain JK. Fractional $\mathrm{CO} 2$ resurfacing: has it replaced ablative resurfacing techniques? Facial Plast Surg Clin North Am. 2013;21(2):213-227.

40. Preissig J, Hamilton K, Markus R. Current laser resurfacing technologies: a review that delves beneath the surface. Semin Plast Surg. 2012;26(3): 109-116.

41. Shamsaldeen O, Peterson JD, Goldman MP. The adverse events of deep fractional $\mathrm{CO}(2)$ : a retrospective study of 490 treatments in 374 patients. Lasers Surg Med. 2011;43(6):453-456 42. Campbell TM, Goldman MP. Adverse events of fractionated carbon dioxide laser: review of 373 treatments. Dermatol Surg. 2010;36(11):1645-1650.

43. Avram MM, Tope WD, Yu T, Szachowicz E Nelson JS. Hypertrophic scarring of the neck following ablative fractional carbon dioxide lase resurfacing. Lasers Surg Med. 2009;41(3):185-188. 44. Svider PF, Carron MA, Zuliani GF, Eloy JA, Setzen M, Folbe AJ. Lasers and losers in the eyes of the law: liability for head and neck procedures. JAMA Facial Plast Surg. 2014;16(4):277-283. 